\title{
An Analysis of Afrocentricity as Theory for Social Work Practice
}

\author{
Dwain A. Pellebon
}

\begin{abstract}
Afrocentricity is developing rapidly within the social work profession as a theory for practice with African Americans. Afrocentric practitioners claim the theory provides a basis for understanding African Americans from an African perspective and cultural value system, and it is the most effective approach to address racial oppression. However, social work has not critically analyzed the merits of Afrocentricity as a source of knowledge to inform the profession. This article takes the initial step to determine whether Afrocentricity is in-fact a theory. Afrocentricity is described, discussed, and analyzed based on current and accepted definitions of theory. The analysis reveals Afrocentric epistemology lacks the rigor to be accepted as an empirically-based theory for practice. The author concludes that Afrocentricity is more accurately categorized as an ideology. Research and practice implications of this conclusion and the need for further critique are discussed.
\end{abstract}

Keywords: Afrocentricity, African-centered, empirically-based theory, cultural competent social work

\section{INTRODUCTION}

Human service professions must constantly adapt to the dynamism of societal change as it relates to politics, culture, technology, and knowledge. For example, political climates can produce legislative outcomes harmful to populations-at-risk (Alzate, 2006). Cultural trends influence inter-group relationships, including race, class, gender, and age cohorts. Medical advances in health and mental health require all helping professions to assess and develop treatments and interventions that produce optimal outcomes. For these reasons and more, social work must be self-critical and adapt to the realities of society. One of the profession's responsibilities to clients and to the profession is to "...critically examine and keep current with emerging knowledge relevant to social work practice (National Association of Social Workers [NASW], 1996, Section 4.01-b)." As the profession examines new ideas, social workers must be willing to accept or reject knowledge based on objective criteria. Practice approaches developed from untested trends, appeals to emo-

Dwain A. Pellebon, Ph.D. is associate professor at The University of Oklahoma School of Social Work, Norman, OK 73069

Copyright $^{\bullet} 2007$ Advances in Social Work Vol. 8 No. 1 (Spring 2007) 169-183. Indiana University School of Social Work. 
tion, and/or oppressor guilt do not promote the well being of client systems or influence change in target systems. Ethical social workers use the most current and verifiable knowledge-base, resources, and skills for competent practice.

For all of the above reasons, this article examines the contribution of Afrocentricity to social work knowledge. It specifically analyzes whether Afrocentricity is technically a theory useful for social work practice. Despite Afrocentricity's brief history, it is described as both a theory and an essential perspective for social work practice with African American clients (Graham, 1999, 2000, 2002, 2005, 2006, 2007; Schiele, 1996). In addition, several social work practice textbooks recognize Afrocentricity as a practice perspective to use with African Americans (Devore \& Schlesinger, 1996; Kirst-Ashman \& Hull, 2006; McCroy, 2007; Miley, O'Melia, \& DuBois, 2007; Poulin, 2005; Weaver, 2005; Zastrow, 2003). Regarding Afrocentricity's contribution to theory, social work textbooks in research (Dudley, 2003) and human behavior in the social environment (Zastrow \& KirstAshman, 2004) assert Afrocentricity as a perspective and worldview for African Americans. Interestingly, Afrocentricity's growing recognition in social work does not result from the profession's scholarly examination of its merits. In fact, the social work literature neglects any critical analysis regarding the perspective's scientific rigor or effectiveness with African American clients.

Considering the relatively new scholarship of Afrocentricity in social work, the profession must assess its standing as a theory and its implications. Afrocentricity's founder encourages such analysis; he suggests that an "Afrocentrist is a scientist... interested in reason, evidence, and falsifiability and in submitting her or his interpretations to rigorous analysis if she or he is studying human behavior" (Asante, 2003, p. 648). Thus, this paper critically examines the merits of Afrocentricity as a theory in terms of its rational conceptualization, scientific rigor, and utility within social work. Afrocentricity's system of interest is to Africans worldwide. To focus the analysis, this article concentrates on Afrocentricity's relevance and application specifically to African Americans as a client system.

After a brief history of Afrocentricity, this article describes its goals and central components. This writer then assesses Afrocentricity using currently accepted standards of theory and knowledge as described by the Commission on Accreditation (Council on Social Work Education [CSWE], 2003) and the profession's values based on the National Association of Social Workers (NASW, 1996).

\section{A BRIEF HISTORY OF AFROCENTRICITY}

Molife Kete Asante is the "founder, principal theorist, and authority of Afrocentrism..." (Turner, 2002, p. 712). In a published interview, he describes his initial inspiration came during his travels in Africa when he realized that it was "crazy" for a Black man to have a European name (Asante, 2003, p. 716). He accepts the conclusion that the primary social crisis for Black Americans is one of culture. A crisis is based on the notion that Eurocentric misrepresentation of African history psychologically dislocates Black Americans (Karenga, 1980). Karenga's philosophy and work to reconstruct African American history in the 1960s was a major influence on Asante's development of Afrocentricity (Asante, 2003, p. 30). 
Asante's (1980) first comprehensive description of his theory laid the foundation for Afrocentricity's development. Within a few years, scholars from history, education, and anthropology criticized the theory's analytical methods and epistemology (Lefkowitz, 1996; Howe, 1999; Ratvich, 1992). These debates prompted Asante $(1987,1988,2000,2003)$ to further develop and defend this new theory. Regardless of the disagreements, Afrocentricity's growing influence is undeniable. It has become a framework to articulate an alternate voice for understanding African culture; it has led to the founding of the Journal of Black Studies, and it has influenced several disciplines, most notably Black studies/African American studies programs in the United States (Turner, 2002, p. 712). Now, Afrocentricity has emerged as a theoretical perspective for social work practice (Schiele, 1996; Graham, 1999).

\section{THE THEORY OF AFROCENTRICITY}

It is important for social workers to understand the theory of Afrocentricity. This writer paraphrases and quotes prominent Afrocentric writers to provide a detailed understanding of the theory and a sense of Afrocentricity's rhetorical style. Asante (2003) defines Afrocentricity:

"Afrocentricity is a mode of thought and action in which the centrality of African interests, values, and perspectives predominate. In regards to theory, it is the placing of African people in the center of any analysis of African phenomena.

Thus, it is possible for any one to master the discipline of seeking the location of Africans in a given phenomenon. In terms of action and behavior, it is a devotion to the idea that what is in the best interest of African consciousness is at the heart of ethical behavior. Finally, Afrocentricity seeks to enshrine the idea that blackness itself is a trope of ethics. Thus, to be black is to be against all forms of oppression, racism, classism, homophobia, patriarchy, child abuse, pedophilia, and white racial domination" (p. 2).

Afrocentricity has several broad goals, but four are pervasive in its literature: 1) Afrocentricity exposes and actively resists "white racial domination" over African Americans; 2) It transforms African Americans toward their cultural center; 3) It converts African Americans to an ideology of values, spirituality, and rituals; and 4) It analyzes disciplines, such as literature, history, linguistics, politics, science, religion, and economics from an Afrocentric perspective (Asante, 2005, pp. 1-13).

The first goal to expose and resist White racial domination is the centerpiece connecting the other three. According to Afrocentricity, this goal is foundational, because African Americans will never thrive until they recognize that the Western world only examines social phenomena from a White perspective, while actively negating African culture. Another problem of Eurocentric thinking is an assumption of universality so pervasive that European Americans place their culture at "the center of the social universe" (Asante, 2003, pp. 2-5). The reason to focus on European culture in America is the belief that culture is the most powerful influence on social, political, educational, economic, scientific, and religious structures 
within society. Thus, the United States, a society built upon the racist domination of other groups, is incapable of developing a humane, pluralistic, or multicultural society. In the end, Eurocentric hegemony “...creates a fundamental human crisis” of unavoidable domination” (Asante, 1998, pp. 5, 22-23).

According to Abarry (1990), the primary objective of Afrocentricity “... is to liberate the research and study of African peoples from the hegemony of Eurocentric scholarship..." (p. 123). Afrocentricity bluntly declares that current methods of inquiry, logic, and research in academia are inappropriate methods to study African Americans. In fact, such approaches to knowledge are "based on an ideology of racial superiority and racial privilege” (Asante, 2006, p. 653). So-called theoretical development through empirical research intentionally oppresses Africans by imposing a racist and sexist interpretation to knowledge. Furthermore, the academy's intentional contrivance of language is an important tool to maintain the hegemony. For example, terms, such as "multicultural," "inclusive," and "ethnic minority" actively promote the dominance and superiority of White Americans. Only the analytical tools of Afrocentricity can discover the truth regarding the African American condition. Afrocentricity's primary tools of analyses are "the twin towers" of tradition and reason (pp. 651-652).

Even African American scholars, educated in the academy, are ineffective using Eurocentric research methods (Asante, 2006, pp. 648-649). African American scholars using empiricism to understand the experience of his or her own culture are "enemies" of African Americans (Turner, 2002, p. 723). These scholars "don't normally speak from a sense of centeredness and intellectual background of Africa or of African America. They speak out of European centeredness.... [Asante] thinks centeredness has to be a sense of fidelity and... integrity... out of your own culture" (Turner, 2002, p. 724). Therefore, a non-Afrocentrist, regardless of race or scholarship, is incapable of developing knowledge that accurately represents the African American collective experience for self-determination and self-definition. The ineffectiveness of African American scholarship is symptomatic of the misorientation resulting from Eurocentric hegemony. Asante (2006) believes that many African American scholars "... are victims of the hegemonic influences of their teachers and are therefore caught in a uniquely stifling bind." In fact, many African American scholars "... write as if they are not just conceptually European but also possess an anti-African agency." Asante maintains his position is not racist or anti-White. On the contrary, it is pro-African to expose the racist and oppressive effects of European mythology (pp. 657-658).

The second goal of Afrocentricity is to return all African Americans to their cultural center. The term "cultural center" refers to the unique African Cultural System, which “... is the first and only reality for African [American] people." The African Cultural System comprises main elements of African symbolism, language, rhythm, spirituality, and values that have always been African culture. However, the system has varied manifestations among Africans globally, because no cultural system is unaffected by new environments (Asante, 2003, pp. 4-5). Variation exists in terms of levels of awareness, manifestation, and participation, but the African Cultural System has not eroded. In fact, Africans “... respond to the same rhythms of the universe, the same cosmological sensibilities, the same gen- 
eral historical reality as the African descended people" (p. 4). Therefore, unless African Americans are "mis-educated, de-centered, or culturally insane," most participate in the African Cultural System" pp. 3-5. Afrocentricity seeks to facilitate African America's connection to the African Cultural System by raising the collective consciousness (pp. 33-37).

According to Afrocentricity, becoming part of the African collective consciousness goes beyond a mere acceptance and understanding of one's African ancestry. The nature of this consciousness involves a collective acceptance of commitments, similar reactions to Eurocentric assaults, cultural destiny, and respect for African ancestors. Only full acceptance pulls the individual to the African cultural center and begins the emergence of Afrocentricity within the person. This comprehensive response is a step towards psychological health and cultural assertiveness, which prevents cultural insanity (Azibo, 1989, p. 178). Finally, the goal of all African Americans, to cross the threshold into collective consciousness, transcends the notion of group unity without Afrocentricity as the organizing paradigm (Asante, 2003, pp. 34-35, 53). This is a logical progression, because it is futile for Afrocentrists to unite with de-centered or mis-oriented African Americans. People of African descent must first experience the transformation to become agents of African culture.

Afrocentricity's transformation is analogous to the Christian notion of religious conversion. Asante (2003) emphasizes, "What [Christians] meant is what I mean ... Your conversion to Afrocentricity becomes total... It supersedes any other ideology because it is the proper sanctification of your own history" (p. 12). Accepting Afrocentricity is a conversion of mind and action. A transformed mind analyzes the world through an African-centered lens and assesses self in relation to that center. After self-examination, analysis extends to all African people in every cultural context. Ultimately, Afrocentrists interpret all social phenomena from this perspective. Asante (2003) points out the "Afrocentrist... studies every thought, action, behavior, and value, and if it is contradictory to [African] culture or our history, it is dispensed with quickly.... Our problems come when we lose sight of ourselves, accept false doctrines, false gods, mistaken notions of what is truly in our history, and assume an individualistic, anti-humanistic, and autocratic posture" (p. 10). In terms of action, it is a continuous process of rejecting the Eurocentric social reality, while embracing all aspects of Afrocentric reality in the midst of a racist society. Afrocentrists assertively challenge Eurocentric perspectives as applied to, or experienced by, African people (p. 35).

Transforming to Afrocentricity leads African Americans to their cultural center and allows them to reach their full potential. In fact, Afrocentricity is an essential reality for African Americans to participate in American society. If one recognizes the power of culture to dominate the minds and behavior of a people (e.g., African Americans), it follows that African Americans must operate within their own culture to respond to European oppression. Without Afrocentricity, Black Americans bring "... nothing to the multicultural table but a darker version of whiteness" (Asante, 1998, p. 8). The solution to White ideological domination is the literal construction of "another reality" to expose, contrast, and critique Eurocentric domination; this alternate reality is the theory of Afrocentricity (Asante, 1998, p. 2). 
The third goal of Afrocentricity is to convert African Americans to an ideology of values, spirituality, and ritual. Asante (2003) developed a belief system referred to as Njia. Translated as "The Way," "Njia is the collective expression of the Afrocentric worldview which is grounded in the historical experience of African people... Njia represents the inspired Afrocentric spirit found in the traditions of AfricanAmericans, and the spiritual survival of an African essence in America" (p. 30). Asante (pp. 137-148) concretely organizes the reconstructive attitudes, values, and behaviors into 10 quarters of teachings, for a total of 234 precepts to learn and internalize. Six examples of precepts from Njia are: "Feeling is before belief and to everyone who feels is given belief" (p. 137); "Refuse to be dogmatic in all things except The Way;" "The revelation of The Way is pure. This is the Truth" (p. 144); "Beware of what you eat because you so easily become what you eat;" "When you feel the wind you are feeling the Presence. Therefore, never ask, where is the Presence? It is everywhere," and "At thirteen years of age every child shall be required to participate in the Mfundalai rite of the coming of age" (p. 147). Practicing Njia in whole is central to developing the fullness of Afrocentricity.

An important ritual in Afrocentricity is "the gathering" ceremony (Asante, 2003). Members meet on Sundays to participate in this meeting, which consists of several rituals. The gathering begins with a libation, which is the pouring of a liquid to invoke the presence of African ancestors, honoring their deeds and accomplishments. With that inspiration, participants engage in forms of creative expression, such as poetry or music. In the rituals called Nommo, participants discuss world problems and consider creative solutions in a manner that validates The Way. A leader reads from Njia's precepts to affirm Afrocentricity's survival and one's own God-force. A second libation, accompanied by a collection of money, affirms prosperity, followed by the final libation that calls upon the next generations of Africans to witness and learn from the current generation. Finally, each attendee raises his and her "right hand into the air for harambees." The word "harambee" means "pulling together" in Kiswahili. A designated person performs the ritual seven times before engaging in fellowship (p. 32). In addition to this weekly celebration, those who follow The Way also celebrate the annual Kwanzaa (p. 114).

The fourth goal of Afrocentricity is to provide a culturally appropriate method of analysis for African Americans. Afrocentricity exposes the Eurocentric historical practice of analyzing African Americans as objects. Placing African Americans into the position of subject allows them to examine phenomena from an African perspective or "location" (Asante, 1993, p. 22). In essence, Afrocentricity is “... a radical critique of the Eurocentric ideology that masquerades as a universal view in the fields of intercultural communication, rhetoric, philosophy, linguistics, psychology, education, anthropology, and history" (Asante, 1998, p. 1). Afrocentricity's approach to the analysis of these disciplines is to interpret and understand information and phenomena using African tradition, history, and culture (Turner, 2002, p. 718).

In summary, Asante presents Afrocentricity as a worldview, paradigm, theory, and ideology of thought and action in which the centrality of African interests, values, and perspectives predominate. It opposes the White domination of Africans by exposing and resisting Eurocentric hegemony. The primary method to over- 
come European oppression is to convert African Americans to Afrocentricity and to return them to their African cultural center. This transformation includes indoctrination into Njia, which provides values, spirituality, and rituals by which the Afrocentrist actualizes his or her potential. Finally, the Afrocentrist uses these truths and knowledge to analyze all social phenomena for the interests of African people.

\section{AN ANALYSIS OF AFROCENTRICITY AS A THEORY}

The task of analyzing Afrocentricity as theory presents a logical dilemma. Specifically, this article uses analytical approaches antithetical to Afrocentricity's unique epistemology. As previously described, Afrocentricity characterizes current conceptualizations of theory, science, and empirical research as oppressive Eurocentric hegemony (Asante, 1998, p. 18). Any assertion that social work research promotes oppression requires examination, because social workers are obligated "to prevent ethical problems from occurring in their studies" using "a variety of safeguards" to protect clients (Dudley, 2003, p. 10). Though Afrocentric writers passionately argue that empirically-based theoretical development is racist and oppressive, they provide no supportive evidence beyond opinion. The social work profession is aware of the potential biases related to politically-driven research, realizes the need for cultural competency in research design, and is aware of the limitations of science measuring social phenomena (Cournoyer \& Klein, 2000, pp. 24-27; Dawson, Klass, Guy, \& Edgley, 1991, p. 72; Dudley, p. 56; Rubin \& Babbie, 2005, pp. 89-94). An interesting observation of Asante's (2003) critique of empiricism is his use of both scientific and nonscientific terminology; for example, Asante describes Afrocentricity as a theory (p. 2), a philosophical perspective (p. 3), an ideology (pp. 3, 12, 28), and a paradigm (Turner, 2002, p. 718). This article's primary analytical goal is to determine whether Afrocentricity is a theory. The analysis examines Afrocentricity in the context of accepted definitions of theory, epistemology, and paradigm. First, this writer describes the essential components of theory, using religion as an analogy, to determine whether Afrocentricity meets its essential criteria. Second, the article examines and comments on Afrocentric epistemology. Third, by understanding its epistemology, the author argues that Afrocentricity's paradigm is ideological. A discussion follows the analysis to consider the implications of accepting Afrocentricity as a paradigm for social work practice.

\section{Is Afrocentricity a Theory?}

Despite Afrocentricity's unique epistemology, accepted definitions of theory must provide the analytical framework. The Council on Social Work Education's (2003) Educational Policy Accreditation and Accreditation Standards guides social work programs on foundation content essential for social work practice. One stated objective is that graduates are able to use "theoretical frameworks supported by empirical evidence" (Program Objectives, Sec. 3.0). Though knowledge is not limited to theoretical frameworks, accepting a premise of empirical support for theory is a logical method to prepare social workers to competently develop and use social work knowledge (CSWE, Foundation Curriculum Content, Sec. 4.3). Knowledge challenged by critical thinking skills and science provides systematic 
methods for social workers to develop interventions, convey their methods to clients, and measure practice outcomes (Cournoyer \& Klein, 2000, p. 2; Dudley, 2003, p. 3; Thomas, 2007, pp. 1-14).

Dawson, Klass, Guy, and Edgley (1991) note variation across definitions of theory; however, they share "...the idea that theories, in as logical terms as possible, [are] a set of general statements that explain or account for some phenomenon..." (p. 70). Examining the definitions of several social science researchers, this observation appears valid (Dudley, 2003; Cournoyer \& Klein, 2000; Neuman \& Kreuger, 2003; Rosenthal, 2001; Rubin \& Babbie, 2005). Of the research writers reviewed, Kerlinger's (1986) definition is the most comprehensive: "A theory is a set of interrelated constructs (concepts), definitions, and propositions that present a systematic view of phenomena by specifying relations among variables, with the purpose of explaining and predicting the phenomena" (p. 9).

This definition details the components and nature of theory. Afrocentricity has defined concepts, propositions, and statements that explain phenomena. However, it is important to realize that rational organization of concepts into explanatory statements is insufficient to conclude their ideas are theory (Dawson, et al., 1991, p. 70; Neuman \& Kreuger, 2003, p. 7). On this basis, one can argue religions are theories. Consider Christianity as an illustration. Christianity has numerous concepts, such as God, creation, sin, grace, repentance, salvation, and sanctification. Vine's (1966) dictionary provides sufficient information to develop these conceptual definitions: 1) God is the creator spirit possessing attributes of omniscience, omnipotence, and, perfection; 2) Supernatural creation is God's ability to bring physical matter into existence independent of nature. The human race exists though the supernatural creation of two progenitors (Adam \& Eve), who are the common ancestors to all humanity; 3) The Sinful nature is a universal spiritual condition of evil resulting from Adam and Eve's disobedience to God's law; 4) Grace is God's conditional spiritual response and solution to forgive human sin; 5) Repentance is the conscious rejection of sin and condition of God's grace; 6) Salvation is the conversion from unbeliever to believer through grace; and 7) Sanctification is the believer's progressive transformation toward perfection. These are a few of the numerous concepts in this complex worldview.

Using these conceptual definitions, many variations of Christianity have developed coherent perspectives to explain social phenomena. A brief description of one variation of evangelical Christianity follows: Because God created humanity, he has the authority to determine morality and power to judge his creation by that standard. The universal human crisis is the sinful nature, which separates humanity from relationship with God. Knowing the propensity for humans to sin, God preordained a plan to forgive sin through the agency of grace, based on the human decision to repent from volitional sin. Anyone who accepts God's grace by faith in this truth experiences salvation. Salvation frees believers from the curse of sin; constrains the sinful nature; and, allows one to live the Christian lifestyle. With power from God's Holy Spirit, the Christian undergoes the sanctification process. This process develops the Christian's ability to obey and please God (Martin, 1975).

The logic of this theology is internally consistent, that is, there are no fallacies of reason within the body of statements. However, it is fallacious to assert that the 
description of reality is objectively true, because it clearly lacks external consistency (Warnick \& Inch, 1989, pp. 75-77). Besides Christian believers, would most grant the premises of God's existence, creation, the sinful nature, grace, or Christianity's conceptualization of morality? What are the observable evidences to support these concepts? If the primary evidences are church tradition, personal testimonies, or biblical authority, then the fallacy of premise arises. On what basis should non-Christians accept church tradition? Are all personal testimonies reliable and consistent? Would most accept the Bible as authoritative valid evidence? The requirement that a valid argument must have external consistency and empirical evidence exposes why religion is not theory.

This is philosophically moot for Afrocentricity, because it does not apply empirical methods to examine its central constructs. Truth is "self-knowledge," and many important concepts in Afrocentricity are beyond measurement (Mazama, 2001, pp. 399-400). Operating under the presumptions that, concepts, such as African Cultural System, Afrocentric transformation, collective consciousness, African centeredness, African interests, ancestral communication, and Eurocentrism are valid constructs, Afrocentrists are not compelled to formulate operational definitions or examine hypothetical relations. From an empirical perspective, without operational definitions, such relations are beyond scientific inquiry (Kerlinger, 1986, p. 4). Afrocentricity's acceptance as empirically-based theory requires internally consistent logic, a broad acceptance of its premises, adequately conceptualized and operationalized constructs, and the ability to test relations between those constructs (Dawson et al., 2002, pp. 70-72; Kerlinger, pp. 19-20; Neuman \& Kreuger, 2003, p. 7; Rubin \& Babbie, 2005, p. 11; Warnick \& Inch, 1989, pp. 75-77). Under such conditions, this analysis concludes that Afrocentricity is not a theory.

\section{Afrocentric Epistomology}

Accepted epistemology for social work practice is not limited to science (Dawson et al., 1991, p. 64; Dudley, 2003, p. 3). Several ways of knowing often produces accurate knowledge about the social world, but epistemological perspectives differ in terms of bias, structure, and reliability (Dudley, 2003, p. 4; Neuman \& Kreuger, 2003, p. 2). Non-scientific ways of knowing influence social work decisions based on informal hypotheses about clients in the environment (Neuman \& Kreuger, 2003, p. 6). Because the social work profession is grounded in empirically-based theories and accepted perspectives, other ways of knowing augment knowledge developed through the scientific method. In place of empiricism, Afrocentricity's epistemology consists of truth based on authority, cultural tradition, and mysticism.

Authority claims knowledge is true, because someone of expertise or importance makes the statement (Kerlinger, 1986, p. 6; Neuman \& Kreuger, 2003, p. 3; Rubin \& Babbie, 2005, p. 13). One limitation of knowledge by authority is the fact that expertise does not guarantee accuracy. For example, Asante (2003) proclaims himself as an authority in African worldviews. The basis of this authority is personal study and his having received the revelation of Afrocentricity as immutable truth (pp. 10, 137-140). Stated expertise in African history and culture alone is insufficient to accept Afrocentricity. When social work confronts theoretical differences, the profession depends upon quantitative and qualitative research to refine 
knowledge; whereas, Afrocentricity has no self-correcting mechanisms based on evidence. To assert Afrocentricity is truth solely on authority is to accept conclusions based on circular reasoning. For example:

Major Premise: Afrocentricity was revealed to Dr. Asante as the only reality for African Americans.

Minor Premise: Afrocentricity teaches that African Americans must be Africancentered for psychological health.

Minor Premise: Afrocentricity is the only way to become African-centered.

Conclusion: Therefore, Dr. Asante's Afrocentricity is the only cultural reality for African Americans psychological health.

Evidence: Dr. Asante developed the one reality for African Americans, i.e., Afrocentricity.

Without evidence for each premise, the conclusion depends upon the major premise resulting in an invalid argument (Warnick \& Inch, 1989, p. 139).

Even less reliable is an individual who is an expert in one field but speaks with authority in another. Some of Dr. Asante's views may inform the profession, however, his expertise in African American studies does not assure his views are relevant to social work practice with African Americans. This conclusion in no way marginalizes disciplines of ethnic study. In the interest of serving populations-atrisk, social work has historically looked to other disciplines to identify knowledge to inform the profession. Some considerations are how the discipline conceptualizes humans in the environment, defines social problems, its philosophical premises, the line of reasoning that follows, and, the practicality of its solutions. For example, Asante (1998) claims that Eurocentric hegemony is a "crisis" for African Americans (p. 23). Afrocentricity's solution is for African Americans to enter the African collective consciousness and pursue psychological liberation through the total acceptance of Afrocentricity (Asante, 2003, p. 62). Given that solution, social work must ask a fundamental question: Is an African American's well being at-risk because she or he does not accept Afrocentricity? One cannot answer the question without determining the validity of two related Afrocentric premises: 1) De-centered African Americans are outside their only cultural reality and, 2) The collective consciousness leads de-centered African Americans to their essential African reality (Asante, 2003, pp. 3-4). Accepting these premises could lead one to conclude the most critical need for African Americans is transformation to Afrocentricity. If converting African Americans to Afrocentricity is a social work goal, what feasible role does a Eurocentric dominated profession (White and de-centered Black professionals, alike) have to participate in the intervention? According to Asante (2003), the role is to move aside so that African Americans can rise "... from the intellectual and spiritual pit that has held our mighty people! Let each person take his post in the vanguard of this collective consciousness of Afrocentricity! Teach it! Practice it! And victory will surely come as we carry out the Afrocentric mission to humanize the Universe" (Asante, 2003, p. 11). Though humanizing the world is compatible with social work's mission, a simple call to convert African Americans to Afrocentricity illustrates how non-professional disciplines may oversimplify com- 
plex social issues. To summarize, knowledge from authority can be accurate or false, depending upon the source of information; the given context; external support for the stated claims; and whether that knowledge can critically inform social work.

Accepting knowledge by Tradition is stating that a belief is true because it was true in the past or that tradition is continuing a practice because it was effective in the past (Dawson, et al., 1991, p. 3; Kerlinger, 1986, p. 6; Neuman \& Kreuger, 2003, p. 3). Sources of traditional knowledge are the family, culture, and historical practices (Rubin \& Babbie, 2005, p. 12). Asante (2003) explicitly grounds Afrocentricity's truth in cultural tradition (p. 30). However, there are several difficulties using cultural tradition as the basis of truth.

First, it is questionable whether tradition is a stable reality. According to Glassie (1995), tradition is a social perception of beliefs and behaviors from which individuals or groups create a future from the past (p. 409). In other words, tradition has aspects of continuity and discontinuity based on an interpretive process imposed by the observer (Handler \& Linnekin, 1984). Asante (2003) believes African cultural tradition transcends social change, thus, it is bounded and equally applicable to all Africans over the centuries (p. 30). This deterministic view suggests an axiomatic bond between corresponding races and cultures in nature (Azibo, 1989, p. 175). This naturally occurring bond, however, is vulnerable to the unnatural interference of group domination. This explains the danger of European hegemony to Africans. As Spencer (2000) points out, "Afrocentricity... suggests that philosophy is at root a racially determined enterprise, with the immediate implication that all epistemology becomes racially relative (p. 191)."

Second, knowledge about ancient traditions depends upon written record, oral testimony, or indirect evidence. Without extant records or reasonable agreement on the original knowledge, tradition is unreliable and is open to challenge and interpretation. For example, Lefkowitz (1996) and Howe (1999) offer challenges to Afrocentricity's interpretations of African history and culture.

A third difficulty, using tradition as truth, is an evident reality that truth changes over time. According to tradition, it was once known that the earth was flat and spirits were the cause of disease and hallucinations (Neuman \& Kreuger, 2003, p. 3; Rubin \& Babbie, 2005, p. 12). Science provided evidence to replace erroneous traditions; likewise, modern social work uses evidence to develop knowledge, not mythology. Afrocentricity provides no evidence that African ancestors can guide living descendants (pp. 8, 32). Nevertheless, this belief qualitatively differentiates de-centered African Americans from Afrocentrists, “... the non-Afrocentric person operates in a manner that is negatively predictable.... Unable to call upon the power of ancestors, because one does not know them; without an ideology of heritage, because one does not respect one's own prophets; the person is like an ant trying to move a large piece of garbage only to find that it will not move" (p. 3). The ant moving a large piece of garbage is an interesting metaphor. African Americans with various cultural and spiritual worldviews moved institutionalized segregation from its foundation during the 1960s Civil Rights Movement without an Afrocentric tradition. The extraordinary changes brought about by the Civil Rights Movement suggest that there is no direct correlation between African mythologi- 
cal homogeneity and social power. Philosophy and religion can use mythological and metaphysical frameworks to function within their disciplines; whereas, social work must be grounded in sound theory and observation.

Mysticism is a way of knowing unobservable phenomena without evidence or a valid logical argument (Cournoyer \& Klein, 2000, p. 5). Many people believe in an invisible Supreme Being, curses, and spirits through faith in place of empirical evidence. This is the primary reason most religions do not classify as theory. Though many religions suggest spiritual existence explains paranormal or supernatural events, it is impossible to forward a valid line of logical reasoning to support the conclusion. As previously pointed out, Afrocentricity has central constructs that are beyond direct measurement and logic.

\section{Afrocentricity as An Ideology}

Afrocentric epistemology depends upon non-scientific knowledge, predominately authority, tradition, and mysticism. The final section of this analysis looks at the similarities and differences between theory and ideology to determine whether Afrocentricity's assumptions and conclusions are ideological constructions.

An ideology is a quasi-theory without the essential features of scientific theory. This closed system explains the social world using fixed assumptions, beliefs, and values that shape its believers. Ideological truth is fixed and immovable by evidence (Neuman \& Kreuger, 2003, p. 45; Rubin \& Babbie, 2005, p. 40). Ideologues promote their views in the popular media, cults, politics, academic disciplines, and religion. Scientists become ideological when they remain fixed in their positions despite contradictory evidence. Social work has ideologues on both sides of many social issues, such as abortion, gay rights, transracial adoption, and evidence-based practice (Rubin \& Babbie, 2005, p. 40). Unlike ideologues, scientists follow accepted norms of the scientific community; that is, an ethos of open and diverse investigation, rigor, organized skepticism, neutrality, communalism, and honesty (Neuman \& Kreuger, 2003, p. 9).

According to Neuman and Kreuger (2003), theory and ideology have similarities and differences. Afrocentricity generally satisfies the similarities between ideology and theory. Both Afrocentricity and scientific theory operate under assumptions, explain social phenomena, provide a system of concepts, discuss conceptual relationships and causality, and, offer an interconnected system of ideas.

Based on Neuman and Kreuger's (2003, p. 45) differentiation between theory and ideology, at each point, Afrocentricity diverges from theory and becomes ideological. Asante (2003) supports the conclusion that Afrocentricity is an ideology. "As the highest, most conscious ideology it makes its points, motivates its adherents, and captivates the cautious by the force of its truth" (pp. 11-12). Without the conditional and negotiated understanding that theory requires, Afrocentricity touts the absolutes of Njia in response to the certainty of Eurocentric hegemony. While theoretical development presumes incompleteness and uncertainty, the collective consciousness leads one closer to the one reality of the African Cultural System. As theoretical knowledge openly expands, Afrocentricity's closed system is primarily committed to conversion into its ideology. While Asante suggests openness to positive and negative testing, he vilifies findings that were produced by so-called 
Western research. Such denunciation restricts objective testing, thereby reducing the likelihood of discrepant findings. It follows that, if the only acceptable evidence supports the structure, there is no basis to change. Science seeks to be objective and detached; whereas, Afrocentricity is an immutable belief system of values that direct attitudes and behavior. "The Way" is not a negotiated system of beliefs, because it presumes to be true. Theory seeks logical consistency, while this analysis finds many issues of internal and external inconsistency within Afrocentricity. Finally, theory transcends social positions. Afrocentric ideology is clearly rooted in a cultural position with predetermined conclusions. Given the ideological nature of Afrocentricity, this analysis has demonstrated the profession must debate its appropriate role in social work practice.

\section{DISCUSSION}

This critique challenges the presumption that Afrocentricity is a practice perspective that is generally applicable to African Americans. By definition, Afrocentricity is an ideology that promotes itself as a valid culture, not a practice paradigm. Mazama (2001) correctly points out that many scholars, claiming adherence to Afrocentricity, clearly misunderstand the paradigm. He points out that some authors do not define the term. Other authors define Afrocentricity, yet misrepresent it as being culturally African, promoting pure African values to benefit all people, or as a worldview with variation (p. 389). Those who would force an ideology into a practice perspective should accurately represent Afrocentricity.

Graham (2007) accurately observes the marginalization of African-centered knowledge in social work. Considering the ideology's goal to liberate African Americans from Eurocentric hegemony, one expects its supporters to assert their perspective. In the spirit of open debate, these views are welcome. However, nonAfrocentrists are minimizing the importance of determining the most appropriate role for this perspective, which suggests a double standard. On one hand, social work insists that empirically-based theories are necessary for competent social work practice; on the other hand, ideology and culture are accepted as sufficiently rigorous for practice with African Americans. There must not be any cultural exceptions for competence practice guided by recognized and empirically-based knowledge (NASW, 1999, Section 4.01).

Social work should acknowledge Afrocentricity in light of the above analysis. There is sufficient evidence to conclude that some African American clients accept Afrocentricity. Hence, social workers will require insight into the culture to be competent practitioners with an Afrocentric client. This approach affirms Afrocentricity as one of many cultures that social workers may be required to understand, depending upon the client (NASW, 1999, Section 1.05). As social workers prepare for clients with that worldview, the implications for research are to identify the prevalence of Afrocentricity in African American communities, the degree of its cultural variation, and potential barriers for cultural competency working with Afrocentric clients. Implications for practice would emerge as research produces answers to these and other research endeavors. Finally, Afrocentricity's views on multiculturalism, cross-cultural practice, gay rights, racially-based personality structures, and self-determination are beyond the 
scope of this article. However, these issues are salient and deserve the profession's attention in the literature.

\section{References}

Alzate, M.M. (2006). Welfare recipients' quality of life: Lessons from the United Nations' Human Development Index for the US welfare policy. European Journal of Social Work, 9, 85-1001.

Asante, M.K. (1980). Afrocentricity: The theory of social change. Buffalo, NY: Amuliefi.

Asante, M.K. (1987). The Afrocentric idea. Philadelphia: Temple University Press.

Asante, M.K. (1988). Afrocentricity. Trenton, NJ: Africa World Press.

Asante, M.K. (2000). The painful demise of Eurocentricism: An African response to critics. Trenton, NJ: Africa World Press.

Asante, M.K. (2003). Afrocentricity: The theory of social change (revised and expanded). African American Images: Chicago Illinois.

Asante, M.K. (2005). “Afrocentricity: Notes on a disciplinary position,” pp. 1-13 in James L. Conyers, Jr. ( ${ }^{\text {rd }}$ ed.), Afrocentric traditions. New Brunswick, NJ: Transaction Publishers.

Asante, M.K. (2006). A discourse on black studies: Liberating the study of African people in the Western academy. Journal of Black Studies, 36(5), 646-662.

Azibo, D.A. (1989). African-centered theses on mental health and a nosology of Black/African personality disorder. Journal of Black Psychology, 15(2), 173-214.

Council on Social Work Education. (2003). Handbook of accreditation standards and procedures (5 $5^{\text {th }}$ ed.). Alexandria, VA: Author.

Cournoyer, D.E., \& Klein, W.C. (2000). Research methods for social work. Needman Heights, MA: Allyn \& Bacon.

Dawson, B.G., Klass, M.D., Guy, R.F., \& Edgley, C.K. (1991). Understanding social work research. Boston, MA: Allyn \& Bacon.

Dudley, J.R. (2003). Research methods for social work: Becoming consumers and producers of research. Boston, MA: Allyn \& Bacon.

Glassie, H. (1995). Tradition. Journal of American Folklore, 108, 395-412.

Goodman, A. (1998). The race pit. Anthropology Newsletter, 39(5), 52.

Graham, M. (1999). The African-centered worldview: Developing a paradigm for social work. British Association of Social Work, 29(2), 252-267.

Graham, M. (2000). Honouring social work principles-exploring the connections between anti-racist social work and African-centered worldviews. Social Work Education, 19(5), 424-435.

Graham, M. (2002). Creating spaces: Exploring the role of cultural knowledge as a source of empowerment in models of social welfare in Black communities. British Journal of Social Work, 32, 35-49.

Graham, M. (2005). Maat: An African-centered paradigm for psychological and spiritual healing. In R. Moody \& W. West (Eds.), Integrating traditional healing practices into counseling and psychotherapy (210-220). Thousand Oaks, CA: Sage Press.

Graham, M. (2006). Black studies and the social work paradigm: Implications of a new analysis. In M.K. Asante \& M. Karenga (Eds.), Handbook of Black studies (304-317). Thousand Oaks, CA: Sage Press.

Graham, M. (2007). Knowledge representation in social work education: Inclusion of marginalized perspectives. International Journal of the Humanities, 3(10), 9-14.

Handler, R., \& Linnekin, J. (1984). Tradition, genuine or spurious. Journal of American Folklore, 97(385), 273-290.

Howe, S. (1999). Afrocentrism: Mythical pasts and imagined homes. London, UK: Verso. 
Karenga, M. (1980). Kawaida theory: An introductory outline. Los Angeles: Kawaida.

Kerlinger, FN. (1986). Foundations of behavioral research. ( $3^{\text {rd }}$ ed.). Orlando, FL: Holt, Rinehart, and Winston.

Kirst-Ashman, K.K., \& Hull, G.H. (2006). Understanding generalist practice. (4 ${ }^{\text {th }}$ ed.). Belmont, CA: Brooks/Cole.

Lefkowitz, M. (1996). Not out of Africa. New York, NY: Harper Collins.

Martin, W.R. (1975). Essential Christianity: A handbook of basic Christian doctrines. Santa Ana, CA: World Vision Publishing.

Miley, K.K., O’Melia, M., \& DuBois, B. (2007). Generalist social work practice: An empowering approach. Boston, MA: Allyn \& Bacon.

National Association of Social Workers. (1996). Code of ethics. Washington, D.C.: Author.

Neuman, W.L., \& Kreuger, L.W. (2003). Social work research methods: Qualitative and quantitative approaches. Boston, MA: Allyn \& Bacon.

Poulin, J. (2005). Strengths-based generalist practice: A collaborative approach. Belmont, CA: Brooks/Cole.

Ravitch, D. (1992). A culture in common. Educational Leadership, 49(4), 8-11.

Rosenthal, J.R. (2001). Statistics and data interpretation for the helping professions. Belmont, CA: Brooks/Cole.

Rubin, A., \& Babbie, E.R. (2005). Research methods for social work (6 $6^{\text {th }}$ ed.). Belmont, CA: Brooks/Cole.

Schiele, J.H. (1996). Afrocentricity: An emerging paradigm in social work practice. Social Work, 41(3), 284294.

Spencer, R. (2000). Assessing issues of race and mixed race in Afrocentric discourse. Passages: Interdisciplinary Journal of Global Studies, 2(2), 186-207.

Thomas, L. (2007). Understanding statistics and research through metaphors: Evidence from cognitive science. Journal of Social Service Research, 34(2), 1-14.

Turner, D.D. (2002). An oral history: Molefi Kete Asante. Journal of Black Studies, 32(6), 711-734

Vine, W.E. (1966). An expository dictionary of New Testament words. Old Tappan, NJ: Fleming H. Revell Company.

Warnick, B., \& Inch, E.S. (1989). Critical thinking and communication: The use of reason in argument. New York, NY: Macmillian Publishing Company.

Weaver, H. (2005). Explorations in cultural competencies: Journeys to the four directions. Belmont, CA: Brooks/Cole.

Zastrow, C. (2003). The practice of social work: Applications of generalist and advanced content. ( $7^{\text {th }}$ ed.). Belmont, CA: Brooks/Cole.

Zastrow, C., \& Kirst-Ashman, K.K. (2004). Understanding human behavior and the social environment $\left(6^{\text {th }}\right.$ ed.). Belmont, CA: Brooks/Cole.

\section{Author's Note:}

Address correspondence to: Dwain A. Pellebon, Ph.D., The University of Oklahoma, School of Social Work, 1005 S. Jenkins Avenue-Rhyne Hall, Norman, OK 73069, USA. e-mail: dpellebon@ou.edu 